Virginia Commonwealth University VCU Scholars Compass

2005

\title{
Passive immunization during pregnancy for congenital cytomegalovirus infection
}

\author{
Giovanni Nigro \\ La Sapienza University, nigrogio@libero.it
}

Stuart P. Adler

Virginia Commonwealth University, sadler@vcu.edu

Renato La Torre

La Sapienza University

Al M. Best

Virginia Commonwealth University

Follow this and additional works at: http://scholarscompass.vcu.edu/pediatrics_pubs

Cart of the Pediatrics Commons

From The New England Journal of Medicine, Nigro, G., Adler, S.P., La Torre, R., et al., Passive immunization during pregnancy for congenital cytomegalovirus infection, Vol. 353, Page 1350, Copyright (C) 2005 Massachusetts Medical Society. Reprinted with permission.

\section{Downloaded from}

http://scholarscompass.vcu.edu/pediatrics_pubs/16

This Article is brought to you for free and open access by the Dept. of Pediatrics at VCU Scholars Compass. It has been accepted for inclusion in Pediatrics Publications by an authorized administrator of VCU Scholars Compass. For more information, please contact libcompass@vcu.edu. 


\title{
Passive Immunization during Pregnancy for Congenital Cytomegalovirus Infection
}

\author{
Giovanni Nigro, M.D., Stuart P. Adler, M.D., Renato La Torre, M.D., \\ and Al M. Best, Ph.D., for the Congenital Cytomegalovirus Collaborating Group*
}

ABSTRACT

From the Departments of Pediatrics (G.N.) and Gynecological Sciences, Perinatology, and Child Health (G.N., R.L.), La Sapienza University, Rome; and the Department of Pediatrics and Biostatistics, Medical College of Virginia Campus, Virginia Commonwealth University, Richmond (S.P.A., A.M.B.). Address reprint requests to Dr. Nigro at Via de Villini 35,00161 Rome, Italy, or at nigrogio@ libero.it.

*Members of the Congenital Cytomegalovirus Collaborating Group are listed in the Appendix.

N Engl J Med 2005;353:1350-62. Copyright (c) 2005 Massachusetts Medical Society.

\section{BACK GROU N D}

Currently, there is no effective intervention for a primary cytomegalovirus (CMV) infection during pregnancy.

\section{METHODS}

We studied pregnant women with a primary CMV infection. The therapy group comprised women whose amniotic fluid contained either CMV or CMV DNA and who were offered intravenous CMV hyperimmune globulin at a dose of $200 \mathrm{U}$ per kilogram of maternal weight. A prevention group, consisting of women with a recent primary infection before 21 weeks' gestation or who declined amniocentesis, was offered monthly hyperimmune globulin (100 U per kilogram intravenously).

\section{RESULTS}

In the therapy group, 31 women received hyperimmune globulin, only 1 ( 3 percent) of whom gave birth to an infant with CMV disease (symptomatic at birth and handicapped at two or more years of age), as compared with 7 of 14 women who did not receive hyperimmune globulin (50 percent). Thus, hyperimmune globulin therapy was associated with a significantly lower risk of congenital CMV disease (adjusted odds ratio, 0.02 ; 95 percent confidence interval, $-\infty$ to $0.15 ; \mathrm{P}<0.001)$. In the prevention group, 37 women received hyperimmune globulin, 6 (16 percent) of whom had infants with congenital CMV infection, as compared with 19 of 47 women (40 percent) who did not receive hyperimmune globulin. Thus, hyperimmune globulin therapy was associated with a significantly lower risk of congenital CMV infection (adjusted odds ratio, 0.32; 95 percent confidence interval, 0.10 to $0.94 ; \mathrm{P}=0.04)$. Hyperimmune globulin therapy significantly $(\mathrm{P}<0.001)$ increased CMV-specific IgG concentrations and avidity and decreased natural killer cells and HLA-DR+ cells and had no adverse effects.

\section{CONCLUSIONS}

Treatment of pregnant women with CMV-specific hyperimmune globulin is safe, and the findings of this nonrandomized study suggest that it may be effective in the treatment and prevention of congenital CMV infection. A controlled trial of this agent may now be appropriate. 
YTOMEGALOVIRUS (CMV) INFECTION IS a common and serious infection occurring in approximately 1 percent of all neonates. ${ }^{1-3}$ Congenital CMV infection is symptomatic in about 10 percent of the infected neonates and is associated with clinically significant neurologic sequelae in almost half of them. In addition, neurologic defects will eventually develop in 8 to 13 percent of neonates with asymptomatic infection. ${ }^{1-3}$ Among women with a primary infection during pregnancy, the rate of fetal infection is approximately 40 percent. ${ }^{1,3,4}$ Although prenatal diagnosis of congenital infection is possible, no prenatal therapy is currently available.

Following the favorable outcome of the infusion of CMV-specific hyperimmune globulin in a fetus with symptomatic CMV infection, ${ }^{5}$ we performed a prospective study of hyperimmune globulin for the treatment or prevention of fetal CMV infection.

\section{METHODS}

PATIENTS AND PROTOCOL

A prospective study was performed from 1995 to 2003. Pregnant women who had a primary CMV infection during or a few months before pregnancy were eligible, as were those who had undergone amniocentesis that revealed CMV in amniotic fluid. Given the likely safety of hyperimmune globulin, the efficacy of immune globulin in animal models, and the off-protocol availability of hyperimmune globulin, none of three ethics committees approved the use of a randomized protocol but did approve the administration of hyperimmune globulin in pregnant women with a confirmed primary CMV infection who had provided written informed consent.

We enrolled 157 pregnant women with primary CMV infection in eight Italian cities (127 in Rome, 17 in Genoa, 8 in Perugia, and 1 each in five other cities) (Fig. 1). Serologic testing was initiated by obstetricians, who routinely screened their patients and then referred women for inclusion in the study. A total of 148 women with no symptoms were identified on the basis of serologic screening, 8 women were identified on the basis of serologic testing after an illness compatible with CMV infection, and 1 woman was identified on the basis of serologic testing conducted after fetal ultrasonography showed abnormal results. All eligible subjects were enrolled. After enrollment, clinical, ultrasonograph- ic, immunologic, and virologic evaluations were performed monthly.

Serologic testing was performed on serum samples obtained at the first obstetrical visit and every one to three months thereafter (mean, six weeks). Primary infection was defined by seroconversion in 131 women who were previously CMV-seronegative, by the presence of CMV-specific IgM antibodies in 4 women, and by the presence ofCMV-specific IgM antibodies and very low but increasing concentrations of CMV-specific IgG antibodies with very low CMV-specific IgG avidity (no more than 25 percent) in 22 women. The four women with CMV-specific IgM antibodies (identified at six, six, seven, and nine weeks of pregnancy) had increasing concentrations of CMV-specific IgG antibodies and increasing CMV-specific IgG avidity and may have become infected up to three months before conception.

Pregnant women were placed in one of two groups. The therapy group consisted of pregnant women who had had a primary infection more than 6 weeks before enrollment who were offered amniocentesis as soon as safely feasible (usually at 20 weeks' gestation or more). If the amniotic fluid contained either CMV DNA on the basis of a polymerase-chain-reaction (PCR) assay or CMV on the basis of culture results, intravenous hyperimmune globulin was offered at a dose of $200 \mathrm{U}$ per kilogram of maternal weight. Additional intravenous doses and intra-umbilical-cord or intraamniotic doses (400 U per kilogram of fetal weight) were used only in the event of ultrasonographic evidence of persistent fetal involvement. Women with CMV-positive amniotic fluid who declined to receive hyperimmune globulin infusions were followed as a comparison group. A total of 79 women underwent amniocentesis, 24 of whom had no evidence of CMV in amniotic fluid. These 24 women were ineligible for the study, but their infants were evaluated at birth.

The prevention group comprised women who had not undergone amniocentesis before or at enrollment. Reasons for not undergoing amniocentesis were a primary infection within 6 weeks before enrollment and a pregnancy of less than 20 weeks' gestation (making the detection of CMV in amniotic fluid unlikely) or a woman's declining to undergo the procedure, regardless of the interval between a primary infection and enrollment. All women were offered intravenous hyperimmune globulin at a dose of $100 \mathrm{U}$ per kilogram every 


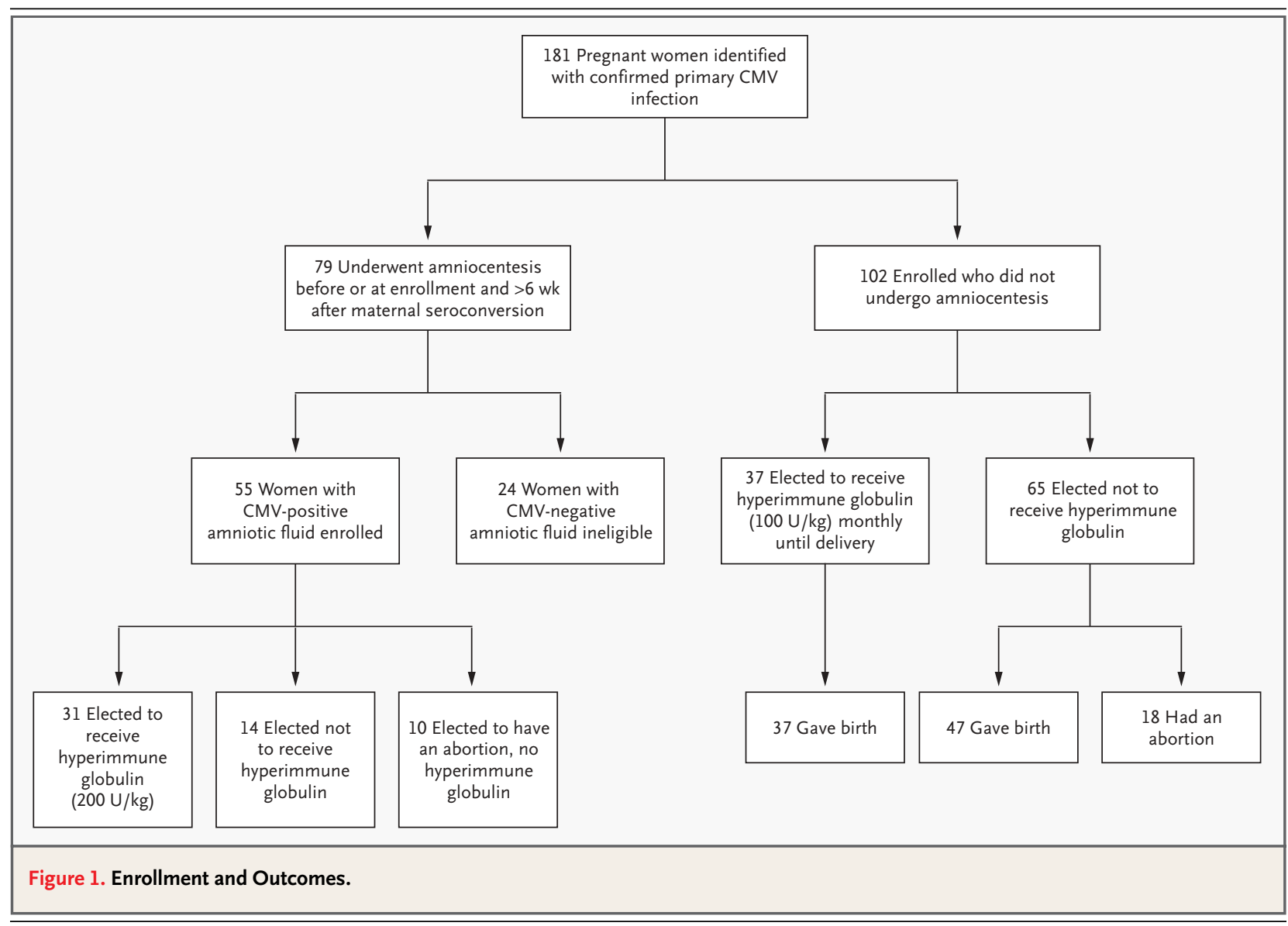

month until delivery. Monthly treatment was selected for this group because of the unknown infection status of their fetuses and thus the desire to sustain antibody concentrations until delivery. Because of the use of multiple doses, a lower dose was selected to reduce costs. Pregnant women who declined to receive hyperimmune globulin were used as a comparison group.

Twenty-eight women (10 in the therapy group and 18 in the prevention group), none of whom received hyperimmune globulin, were excluded from follow-up when their pregnancies were aborted (27 elective and 1 spontaneous). The rate of infection among the fetuses of the 18 women who aborted in the prevention group was not determined.

Neonatal evaluations included testing of urine for CMV by two weeks of age; physical examination; blood-cell and platelet count; measurement of aminotransferase, bilirubin, and creatinine concentrations; ophthalmoscopy; cerebral and abdominal ultrasonography; and brain-stem auditory evoked responses. Among fetuses with suspected neurologic involvement, cerebrospinal fluid was obtained and electroencephalography, cerebral computed tomography, and magnetic resonance imaging were performed.

Symptomatic congenital CMV disease was defined by fetal or infant death or by neurologic involvement, including microcephaly (head circumference below the 5th percentile for gestational age ${ }^{6}$ ), periventricular calcifications, cerebral dysplasias, seizures in an infant with CMV DNA in cerebrospinal fluid, ventricular and subependymal abnormalities, chorioretinitis, or auditory impairment. Intrauterine growth restriction was defined by head and abdominal circumferences that were below the 10th percentile for fetuses of similar age. ${ }^{7} \mathrm{CMV}$ disease at two years of age or older was defined by mental retardation (IQ below 70) or motor delay, or both, and auditory or visual impairment. The Gesell, Bayley, and Stanford-Binet scales were used for evaluation. During the first two years of life, the children's hearing was assessed by brain-stem auditory evoked responses. The threshold for normal hear- 


\begin{tabular}{|c|c|c|c|c|c|c|}
\hline \multirow[t]{2}{*}{ Characteristic } & \multicolumn{3}{|c|}{ Therapy Group ( $N=45$ ) } & \multicolumn{3}{|c|}{ Prevention Group $(\mathrm{N}=84)$} \\
\hline & $\begin{array}{l}\text { Received HIG } \\
\quad(N=31)\end{array}$ & $\begin{array}{l}\text { No HIG } \\
(\mathrm{N}=14)\end{array}$ & P Valuet & $\begin{array}{l}\text { Received HIG } \\
\quad(\mathrm{N}=37)\end{array}$ & $\begin{array}{l}\text { No HIG } \\
(\mathrm{N}=47)\end{array}$ & P Value' \\
\hline Maternal age at enrollment (yr) & & & 0.72 & & & 0.32 \\
\hline Median & 29 & 27 & & 30 & 29 & \\
\hline Interquartile range & $25-32$ & $26-32$ & & $28-33$ & $27-32$ & \\
\hline No. of primary maternal infections & & & 0.21 & & & 0.38 \\
\hline Identified by ultrasonography & 1 & 0 & & 0 & 0 & \\
\hline Identified by maternal screening & 27 & 14 & & 36 & 43 & \\
\hline Identified by maternal symptoms & 3 & 0 & & 1 & 4 & \\
\hline $\begin{array}{l}\text { No. of primary maternal infections identified by IgM } \\
\text { antibodies alone }\end{array}$ & 2 & 2 & 0.58 & 0 & 0 & ND \\
\hline Wk of gestation at maternal infection & & & 0.79 & & & $<0.01$ \\
\hline Median & 12 & 11 & & 14 & 20 & \\
\hline Interquartile range & $8-15$ & $9-18$ & & $8-16$ & $14-26$ & \\
\hline $\begin{array}{l}\text { No. of fetuses with ultrasonographic evidence } \\
\text { of disease }\end{array}$ & 15 & 7 & 0.92 & NA & NA & NA \\
\hline Copies of CMV DNA in amniotic fluid $\left(\times 10^{4}\right)$ & & & 0.15 & & & \\
\hline Median & 17 & 28 & & NA & NA & NA \\
\hline Interquartile range & $1-37$ & $13-85$ & & NA & NA & \\
\hline No. of women with CMV-positive amniotic fluid & & & 0.47 & NA & NA & NA \\
\hline By PCR alone & 11 & 5 & & & & \\
\hline By culture alone & 3 & 0 & & & & \\
\hline By PCR and culture & 17 & 9 & & & & \\
\hline Wk of gestation for HIG administration & & & NA & & & NA \\
\hline Median & 24 & NA & & 19 & NA & \\
\hline Interquartile range & $22-27$ & NA & & $16-23$ & NA & \\
\hline Doses of HIG per woman & & & NA & & & NA \\
\hline Median & 1 & NA & & 5 & NA & \\
\hline Interquartile range & $1-1$ & NA & & $4-6$ & NA & \\
\hline $\begin{array}{l}\text { No. of women given intra-umbilical-cord or } \\
\text { intraamniotic HIG (or both) }\end{array}$ & 9 & NA & NA & NA & NA & NA \\
\hline Fetal infection identified (wk of gestation) & & & 0.14 & & & NA \\
\hline Median & 21 & 23 & & NA & NA & \\
\hline Interquartile range & $19-25$ & $20-32$ & & NA & NA & \\
\hline $\begin{array}{l}\text { Time between maternal infection and HIG admin- } \\
\text { istration (wk) }\end{array}$ & & & NA & & & NA \\
\hline Median & 13 & NA & & 6 & NA & \\
\hline Interquartile range & $10-15$ & NA & & $5-9$ & NA & \\
\hline $\begin{array}{l}\text { Time between fetal diagnosis and HIG admin- } \\
\text { istration (wk) }\end{array}$ & & & NA & & & NA \\
\hline Median & 2 & NA & & NA & NA & \\
\hline Interquartile range & $1-4$ & NA & & NA & NA & \\
\hline $\begin{array}{l}\text { * HIG denotes hyperimmune globulin, and NA not ap } \\
\text { T Groups were compared by Fisher's exact test or by } \mathrm{V} \\
\text { When the weeks of gestation at the time of maternal } \\
\text { to estimate the time of maternal infection. }\end{array}$ & $\begin{array}{l}\text { icable. } \\
\text { Icoxon's rank-su } \\
\text { fection were kno }\end{array}$ & $\begin{array}{l}\text { test. } \\
\text { only as a }\end{array}$ & nge, the ave & ge of the end poi & s of the rar & e was usec \\
\hline
\end{tabular}




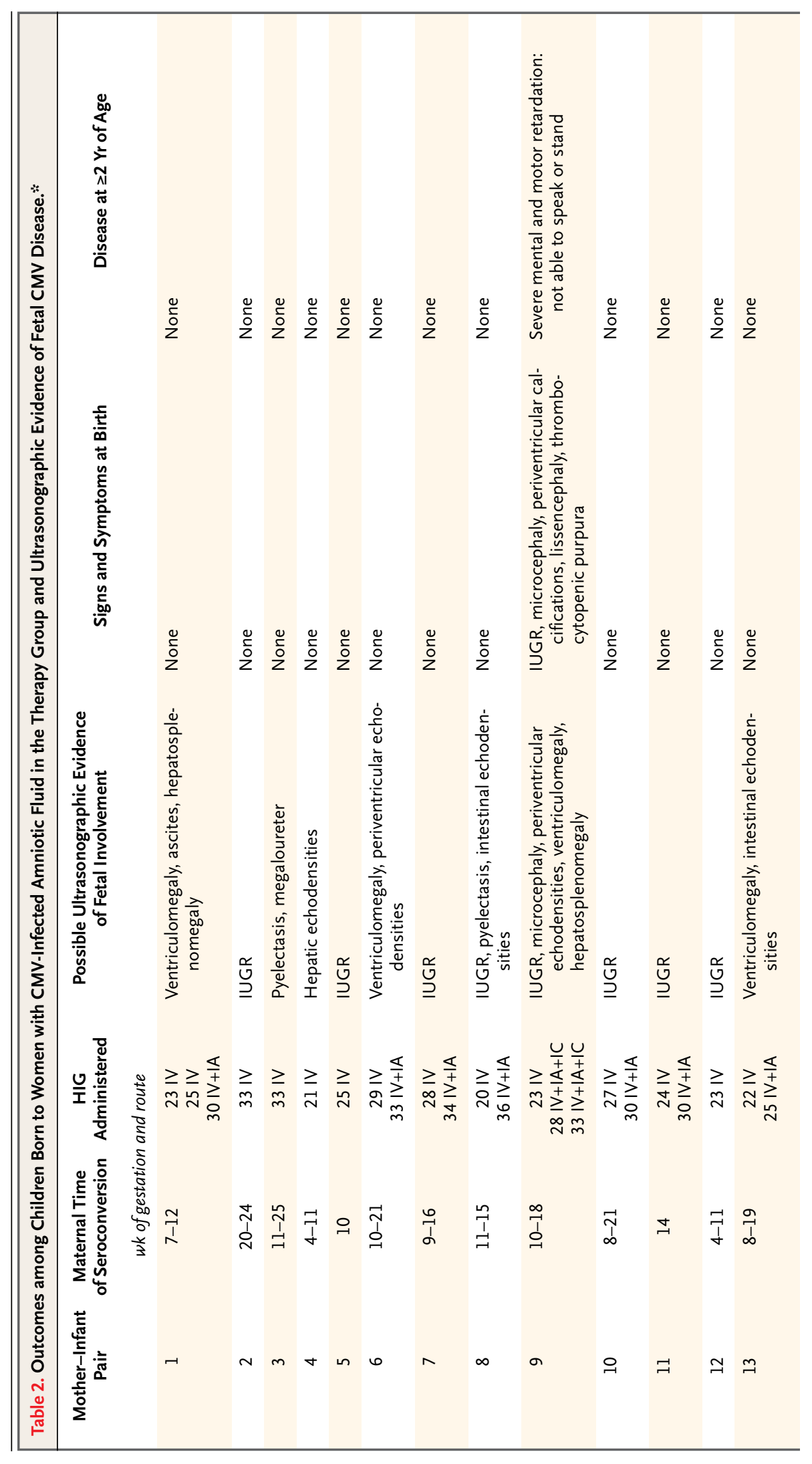




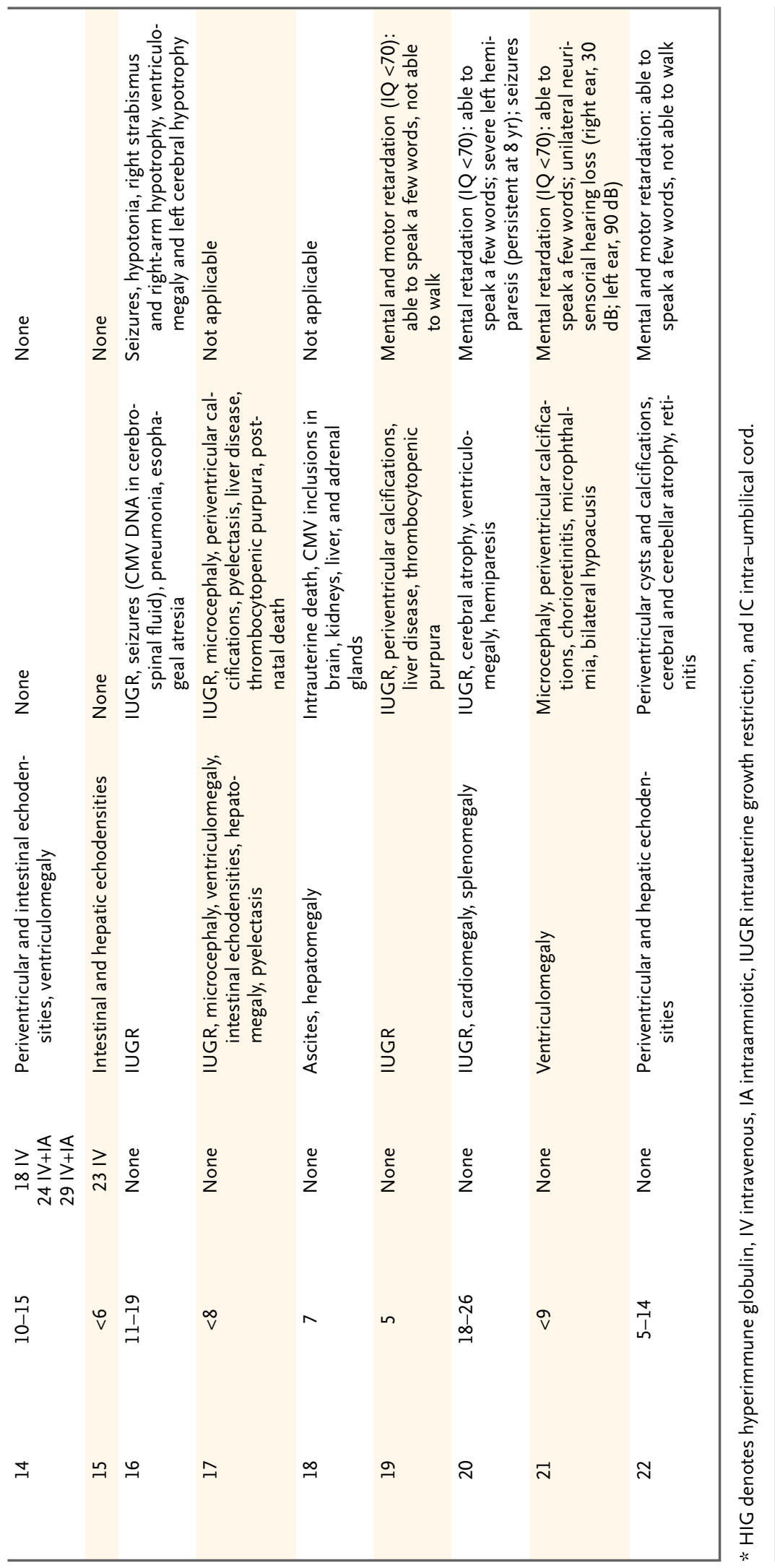


ing was defined as 0 to $20 \mathrm{~dB}$. Abnormal responses were defined as mild (threshold, 21 to $45 \mathrm{~dB}$ ), moderate (threshold, 46 to $70 \mathrm{~dB}$ ), or severe (threshold, at least $71 \mathrm{~dB}$ ).

Each neonate was evaluated by a neonatologist, and follow-up of all neonates was done by a single physician.

\section{HYPERIMMUNE GLOBULIN}

CMV hyperimmune globulin (Cytotect Biotest) has a half-life of approximately 22 days, has been used safely in other studies, and has antiviral and immunomodulatory effects. ${ }^{8-12}$ The mean titer of IgG antibodies against CMV glycoprotein B was 1:409,600, and the mean IgG avidity was 75.9 percent. The infusion rate was $25 \mathrm{U}$ per minute for 30 minutes and then $50 \mathrm{U}$ per minute until the calculated dose was administered.

\section{VIROLOGIC METHODS}

CMV was isolated by means of a shell vial. CMV DNA was detected with the use of DNA extraction and nested PCR. ${ }^{13}$ To determine the number of genomic copies, competitive quantitative PCR was performed with the use of CMV-ibridoquant (Amplimedical Bioline).

\section{ANTIBODY DETECTION}

CMV-specific IgG and IgM antibodies were detected by an enzyme immunoassay kit (Radim). Duplicate serum samples were tested. Antibody concentrations (in units per milliliter) were calculated from a calibration curve. CMV-specific IgG avidity was measured with a kit from Bouty (Sesto). On the basis of published data and data from the manufacturer, avidities of less than 25 percent indicated an infection within the previous three months. ${ }^{14}$

\section{IMMUNOLOGIC STUDIES}

Immunologic studies were performed in a subgroup of women who received hyperimmune globulin, before and after infusions, and in untreated women at enrollment and after two months. The cytotoxic activity of natural killer cells in response to CMV-infected cells was determined on $\mathrm{K} 562$ cells labeled with chromium- 51 by means of a fourhour ${ }^{51} \mathrm{Cr}$-release assay and was expressed as a specific percentage of cytotoxicity at various effectorto-target ratios (100:1, 50:1, 25:1, and 12.5:1). ${ }^{15}$ The percentage and number of CD3+ T cells, CD4+ (helper-inducer) T cells, CD8+ cells (cytotoxic suppressor lymphocytes), CD16+56+ cells (natural kill- er cells), CD19+ B cells, and HLA-DR + cells (activated lymphocytes, monocytes, and macrophages) in blood were determined by flow cytometry. ${ }^{15,16}$

\section{STATISTICAL ANALYSIS}

Fisher's exact test or Wilcoxon's rank-sum test was used for univariate analysis. Where appropriate, a t-test was used on log-transformed data. An exact logistic-regression analysis determined the factors associated with congenital infection or disease (LogXact, version 4.0.2, Cytel Software). Using the methods of Hosmer and Lemeshow, we evaluated unadjusted odds ratios for potential inclusion in a model. ${ }^{17}$ All those with an initial P value of less than 0.2 were included in the multivariate model.

RESULTS

\section{THERAPY GROUP}

The therapy group consisted of 31 women who received at least one infusion of hyperimmune globulin within 1 to 9 weeks (mean, 3.2 weeks) after the diagnosis of fetal infection by amniocentesis and 14 women who declined to receive hyperimmune globulin. The baseline variables in Table 1 were similar in the two subgroups of women. Because of ultrasonographic evidence of persistent fetal disease, nine women ( 29 percent) received one or two additional intravenous infusions two to six weeks apart and intra-umbilical-cord or amniotic infusions of hyperimmune globulin or both (Tables 1 and 2).

Of the 31 women receiving hyperimmune globulin in the therapy group (15 of whom were carrying a fetus with ultrasonographic evidence of CMV infection), only 1 delivered an infant with CMV disease, whereas 7 of 14 women who did not receive hyperimmune globulin had affected infants. For infants with ultrasonographic evidence of disease before birth, the signs and symptoms of fetal disease, disease at birth, and outcome at two years of age or older are shown in Table 2. Each infant with a symptomatic infection at birth had disease at two years of age, and each had ultrasonographic evidence of fetal disease. No infant without ultrasonographic evidence of fetal disease had symptoms at birth or subsequently had sequelae.

Table 3 lists potential predictors of congenital disease among mothers in the therapy group. A logistic-regression model showed that two predictors were associated with a significantly reduced or increased risk of congenital disease. These were receipt of hyperimmune globulin (adjusted odds ra- 


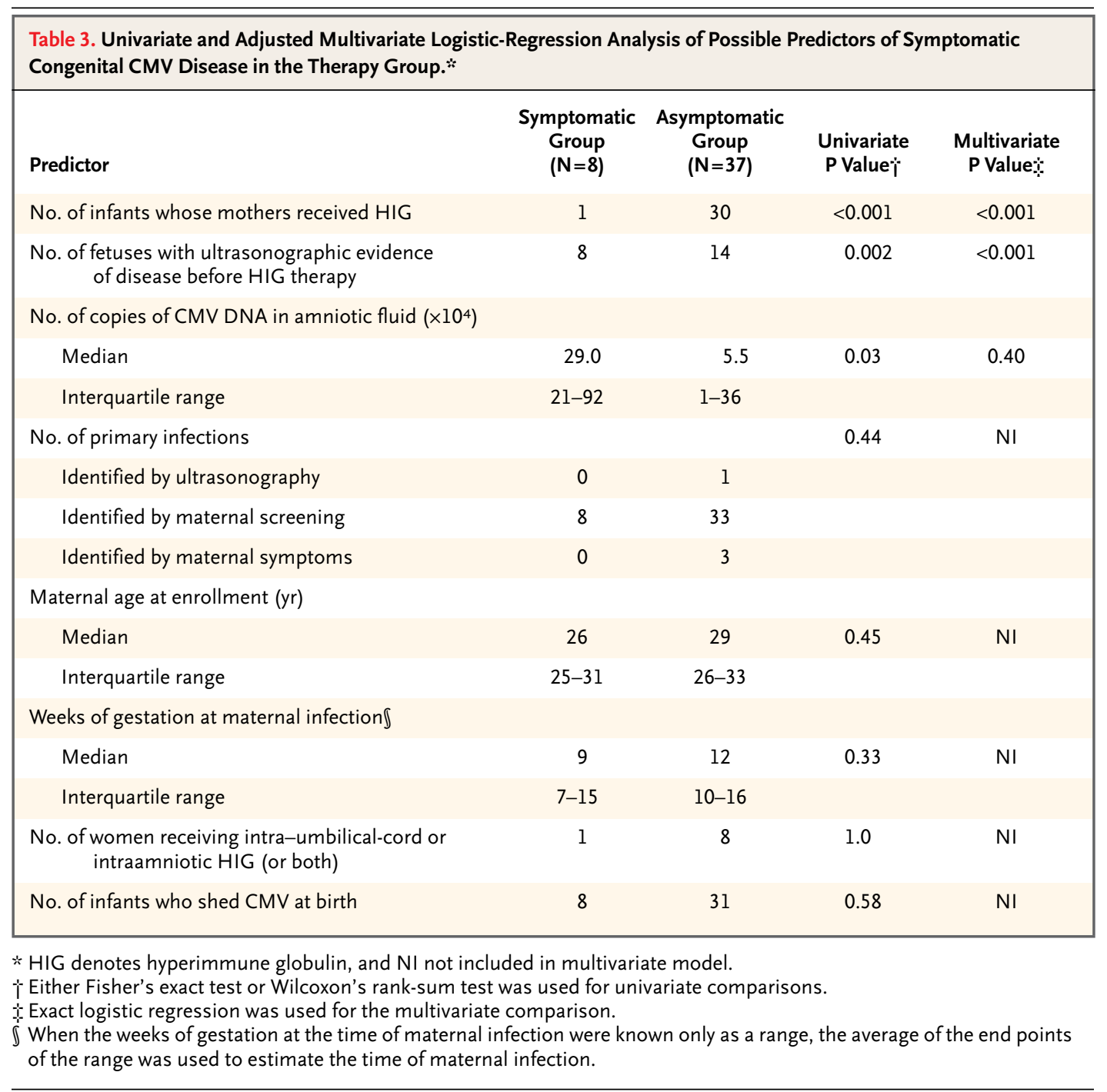

tio, $0.02 ; 95$ percent confidence interval, $-\infty$ to $0.15 ; \mathrm{P}<0.001)$ and the presence of fetal disease (adjusted odds ratio, 60.0; 95 percent confidence interval, 5.5 to $\infty$; $\mathrm{P}<0.001$ ), respectively. We repeated the logistic-regression model after excluding data on seven women whose diagnosis of primary infection was based solely on the presence of CMV-specific IgM antibodies in their serum or whose infants were not infected at birth. After these exclusions, the receipt of hyperimmune globulin remained a significant predictor of a reduced risk of neonatal disease (adjusted odds ratio, 0.03; 95 percent confidence interval, $-\infty$ to $0.27 ; \mathrm{P}=0.001$ ) and the presence of fetal disease remained a significant predictor of an increased risk (adjusted odds ratio, 42.0; 95 percent confidence interval, 38.8 to $\infty ; \mathrm{P}=0.001$ ).

\section{PREVENTION GROUP}

The prevention group consisted of 37 women treated with monthly infusions of hyperimmune globulin 2 to 11 weeks (mean, 6.6) after presumed seroconversion; the number of infusions ranged from 2 to 7 (mean, 4.8). Five women missed infusions in the third trimester. Also in this group were 47 pregnant women who did not receive hyperimmune globulin. Of the 37 women who received hyperimmune globulin, 6 (16 percent) had infants with congenital infection. This rate was significantly lower $(\mathrm{P}=0.02)$ than the 40 percent rate among the women who did not receive hyperimmune globulin (19 of 47).

Significantly associated with the receipt of hyperimmune globulin was a younger gestational age at maternal infection, as compared with that among 
untreated women (Table 1). This occurred because women who declined to undergo amniocentesis were also more likely to decline hyperimmune globulin therapy. Women who were at 21 weeks of gestation or more at infection constituted 47 percent of the women declining hyperimmune globulin but only 13 percent of those receiving hyperimmune globulin. Thus, the prevention group contained two subgroups, those infected before 21 weeks' gestation (when amniocentesis was less likely to be predictive) and those infected at 21 weeks' gestation or more but who declined amniocentesis. The difference in infection rates between these two groups was not significant $(\mathrm{P}=0.20)$ (Table 4).

A logistic-regression model identified only one predictor associated with a significant reduction in the risk of congenital infection (Table 4) - receipt of hyperimmune globulin (adjusted odds ratio, 0.32; 95 percent confidence interval, 0.10 to 0.94 ; $\mathrm{P}=0.04$ ). For women receiving hyperimmune globulin, there was no association between congenital infection and the average number of doses of hyperimmune globulin received, gestational age at the time of treatment, or the interval between infection and receipt of hyperimmune globulin (Table 4).

In the prevention group, three women who did not receive hyperimmune globulin became infected at 9,10 , and 18 weeks' gestation, and gave birth to infants with severe symptomatic infections. None of the infants born to women who received hyperimmune globulin had symptoms at birth. There was no significant difference in the rates of symptomatic infection between infants of treated women and infants of untreated women in the prevention group.

Finally, we considered all women. In the prevention group, 47 women did not receive hyperimmune globulin, 19 of whom had infected neonates; in the therapy group, 55 women (including 10 who had an abortion) either did not receive hyperimmune globulin or received it after CMV disease was diagnosed in their fetus and 24 women had CMV-negative amniotic fluid, 3 of whom had infected but asymptomatic infants. These 126 women had a mean $( \pm S D)$ gestational age at infection of $14.3 \pm 7$ weeks, and 56 percent ( 71 women) had infected newborns. This rate was significantly higher (odds ratio, 0.15; 95 percent confidence interval, 0.06 to 0.38 ; $\mathrm{P}<0.001$ ) than the 16 percent rate (6 of 37) among women who received hyperimmune globulin, who were at a mean of $13.2 \pm 5.5$ weeks of gestation at infection. Overall, CMV disease occurred in 28 percent ( 10 of 36 ) of the infants infected in utero whose mothers had a mean gestational age at infection of $16 \pm 9$ weeks and who did not receive hyperimmune globulin. This rate was significantly higher (odds ratio, 0.07; 95 percent confidence interval, 0.01 to $0.60 ; \mathrm{P}=0.003$ ) than the 2.7 percent rate among the infants of women who received hyperimmune globulin (in the prevention and therapy groups) and who had a mean gestational age at infection of $14 \pm 4$ weeks; in this group, CMV disease developed in only 1 of 37 infants infected in utero.

\section{IMMUNOLOGIC STUDIES}

We performed immunologic assays in women available for follow-up evaluations in Rome. Treatment with hyperimmune globulin in prevention or therapy doses was significantly associated with increased CMV-specific IgG concentrations and IgG avidity in serum after infusions (measured within $30 \mathrm{~min}$ utes after infusion in 24 patients and within six days in 8 patients) to values similar to those present at delivery (Table 5). Women receiving hyperimmune globulin had CMV-specific IgG concentrations and avidities at delivery similar to those among untreated women (Table 5).

The number and percentage of immune cells were measured at enrollment and about eight weeks after hyperimmune globulin infusion in 26 women and at enrollment and eight weeks later in 21 untreated women. There were no significant changes in values in the untreated women. Women who received hyperimmune globulin had a significant decrease of approximately 33 percent of the percentage of the total natural killer cells and HLA-DR+ cells and of the natural killer cell activity and a 40 percent decrease in the absolute number of HLA-DR+ and natural killer cells but no significant changes in $\mathrm{CD} 3+, \mathrm{CD} 4+, \mathrm{CD} 8+$, or CD19+ responses.

\section{ADVERSE EVENTS}

No adverse events were associated with hyperimmune globulin infusions.

\section{DISCUSSION}

Our observations are consistent with the natural history of CMV infection and pregnancy. For women infected before conception (who are seropositive), the rate of transmission of CMV from mother to fetus usually ranges from 0.5 to 2 percent. ${ }^{1,18}$ However, for women with a primary infection dur- 


\begin{tabular}{|c|c|c|c|c|}
\hline Predictor & Infected Group & $\begin{array}{l}\text { Uninfected } \\
\text { Group }\end{array}$ & $\begin{array}{l}\text { Univariate } \\
\text { P Value' }\end{array}$ & $\begin{array}{l}\text { Multivariate } \\
\text { P Valuef }\end{array}$ \\
\hline All women in the prevention group & 25 & 59 & & \\
\hline Infants whose mothers received HIG — no. (\%) & $6(24)$ & $31(52)$ & 0.02 & 0.04 \\
\hline Time of primary infection - no. of women $\mathbb{S}$ & & & 0.20 & 0.49 \\
\hline$<21$ weeks of gestation & 14 & 43 & & \\
\hline$\geq 21$ weeks of gestation & 11 & 16 & & \\
\hline Maternal age at enrollment - yr & & & 0.78 & ND \\
\hline Median & 30 & 29 & & \\
\hline Interquartile range & $27-32$ & $27-33$ & & \\
\hline No. of primary infections & & & 0.62 & ND \\
\hline Identified by maternal screening & 22 & 57 & & \\
\hline Identified by maternal symptoms & 3 & 2 & & \\
\hline $\begin{array}{l}\text { No. of infants whose mothers had a CMV-specific } \\
\text { increase in IgG by delivery/total no. tested }\end{array}$ & $5 / 8$ & $13 / 19$ & 1.00 & ND \\
\hline $\begin{array}{l}\text { No. of infants whose mothers had an increase in } \\
\text { CMV-specific lgG avidity by delivery/total } \\
\text { no. tested }\end{array}$ & $8 / 8$ & $19 / 19$ & 1.00 & ND \\
\hline $\begin{array}{l}\text { No. of infants whose mothers had an increase in } \\
\text { CMV-specific IgG after HIG by infusion/to- } \\
\text { tal no. tested }\end{array}$ & $4 / 4$ & $11 / 11$ & 1.00 & ND \\
\hline $\begin{array}{l}\text { No. of infants whose mothers had a decrease in nat- } \\
\text { ural killer cells by delivery/total no. tested }\end{array}$ & $2 / 8$ & $8 / 14$ & 0.63 & ND \\
\hline Women who received HIG & 6 & 31 & & \\
\hline No. of HIG doses per woman & & & 0.08 & 0.75 \\
\hline Median & 4 & 5 & & \\
\hline Interquartile range & $3-5$ & $4-6$ & & \\
\hline Wk of gestation for HIG administration & & & 0.08 & 0.59 \\
\hline Median & 23 & 18 & & \\
\hline Interquartile range & $20-27$ & $15-22$ & & \\
\hline $\begin{array}{c}\text { Time between maternal infection and HIG } \\
\text { administration - wk } 9\end{array}$ & $6.7 \pm 1.9$ & $6.6 \pm 2.8$ & 0.78 & ND \\
\hline
\end{tabular}

* HIG denotes hyperimmune globulin, and ND not done.

$\dagger$ Either Fisher's exact test or Wilcoxon's rank-sum test was used for the univariate comparisons.

Exact logistic regression was used for the multivariate comparison.

$\int$ When the weeks of gestation at the time of maternal infection were known only as a range, the average of the end points of the range was used to estimate the time of maternal infection.

If Plus-minus values are means $\pm \mathrm{SD}$.

ing pregnancy, reported rates of maternal-to-fetal transmission range from 40 to 50 percent. ${ }^{1,3,4}$ Overall, transmission occurred among 56 percent of women with a primary infection and 16 percent of those receiving hyperimmune globulin.

The highest rate of symptomatic congenital infection and sequelae - about 25 percent - occurs among infected infants whose mothers had a primary infection during pregnancy. ${ }^{19}$ The rate of CMV disease among infected infants of seropositive mothers is 8 percent or less. ${ }^{19}$ We observed CMV disease in 28 percent of congenitally infected infants whose mothers did not receive hyperimmune globulin. This rate is compatible with previous observations. Among the 37 congenitally infected infants of women who received hyperimmune globulin, only 1 ( 3 percent) had CMV disease.

Neonatal-transfusion studies first showed that antibodies against CMV were protective against CMV disease. ${ }^{20,21}$ Symptomatic CMV infections de- 


\begin{tabular}{|c|c|c|c|c|c|c|}
\hline Group & $\begin{array}{l}\text { No. of Women } \\
\text { with Results }\end{array}$ & $\begin{array}{c}\text { CMV-Specific } \\
\text { IgG Concentration }\end{array}$ & P Value' & $\begin{array}{c}\text { No. of Women } \\
\text { with Results }\end{array}$ & $\begin{array}{l}\text { CMV-Specific } \\
\text { IgG Avidity }\end{array}$ & P Value \\
\hline & & $U / m l$ & & & $\begin{array}{c}\text { \% high-avidity } \\
\text { antibodies }\end{array}$ & \\
\hline \multicolumn{7}{|l|}{ Therapy group } \\
\hline Before HIG & 10 & $5.5(3.4-9.7)$ & $<0.001$ & 13 & $11.1(8.5-15.6)$ & $<0.001$ \\
\hline After HIG & 10 & $12.4(8.0-19.0)$ & & 13 & $24.8(18.6-31.4)$ & \\
\hline At enrollment & 12 & $7.2(5.0-11.4)$ & $<0.001$ & 12 & $6.7(4.1-10.6)$ & $<0.001$ \\
\hline At delivery & 12 & $17.4(11.7-26.0) \ddagger$ & & 12 & $32.5(29.3-41.7)$ & \\
\hline \multicolumn{7}{|c|}{ Prevention group } \\
\hline Before HIG & 9 & $6.9(3.7-12.7)$ & $<0.001$ & 15 & $15.1(12.7-18.0) \doteqdot$ & $<0.001$ \\
\hline After HIG & 9 & $11.8(7.5-18.5)$ & & 15 & $25.1(19.8-31.7)$ & \\
\hline At enrollment & 20 & $4.1(2.8-6.1)$ & $<0.001$ & 20 & $8.1(5.5-12.0)$ & $<0.001$ \\
\hline At delivery & 20 & $11.7(8.3-16.5)$ & & 20 & $29.6(24.1-36.3)$ & \\
\hline \multicolumn{7}{|c|}{ Untreated group } \\
\hline At enrollment & 17 & $6.6(4.5-9.5)$ & 0.54 & 17 & $8.7(6.2-12.1)$ & $<0.001$ \\
\hline At delivery & 17 & $7.5(4.9-11.4)$ & & 17 & $21.5(15.3-30.1)$ & \\
\hline
\end{tabular}

* Values are geometric means (and 95 percent confidence intervals). HIG denotes hyperimmune globulin.

$\uparrow P$ values were calculated with the use of a paired t-test on log-transformed data and are for the comparison of values either before and after treatment or at enrollment and at delivery.

$\lceil\mathrm{P}<0.006$ for the comparison with the untreated group. All other comparisons of IgG concentrations and avidity between the untreated group and the therapy and prevention groups either before or after treatment or at enrollment or delivery were not significantly different $(P>0.05)$.

veloped in premature newborns born to CMV-seronegative mothers after the receipt of blood products, whereas premature newborns born to CMVseropositive mothers became infected but remained asymptomatic after receiving blood products. By eight weeks of age, only 10 to 20 percent of maternal antibody against $\mathrm{CMV}$ remains. Even at this age, newborns are protected against severe CMV disease. ${ }^{22}$ Impressive results have also been observed in pregnant guinea pigs challenged with guineapig CMV before or after passive administration of antiserum to either whole virus or to a specific guinea-pig-CMV glycoprotein $\mathrm{B}$ that induces neutralizing antibodies. ${ }^{23,24}$

Because of the availability of serial serum samples from each subject, we could identify the time of maternal infection for nearly all subjects to within an average range of six weeks. The majority of women were infected in the first trimester (42 percent) or the second trimester (50 percent) of pregnancy. Thus, the possible efficacy of hyperimmune globulin therapy for maternal infection in the last trimester is uncertain. The infusion of hyperimmune globulin into amniotic fluid appeared ineffec- tive. The pregnant woman who delivered the only symptomatic neonate among all 68 treated women received both intraamniotic and intra-umbilicalcord hyperimmune globulin (Table 2).

Treatment with hyperimmune globulin decreased the number and percentage of both natural killer cells and HLA-DR+ cells, as compared with these values among untreated women with active CMV infection. This effect may be related to the ability of hyperimmune globulin to inhibit the replication of CMV, since at the onset of a primary CMV infection, the numbers of natural killer cells and HLA-DR+ cells are increased. ${ }^{25,26}$ However, the increased number and activity of these immune cells are associated with a high level of production of cytokines such as tumor necrosis factor $\alpha$, which can contribute to immune-mediated fetal damage. 27,28 Thus, hyperimmune globulin may diminish the pathogenic effects of CMV either by neutralization or immunomodulatory effects.

Hyperimmune globulin appeared less effective for the prevention of fetal infection than for the treatment of fetuses already infected. Several factors may explain this finding. First, some of the six 
infected infants may have been infected before their mothers received hyperimmune globulin. Second, the prevention group received a lower dose of hyperimmune globulin than the therapy group, although it was administered monthly in the former group to sustain antibody concentrations until delivery. Third and most likely is that the mechanism of action of hyperimmune globulin differs in the prevention and therapy groups. For the prevention of fetal infection, hyperimmune globulin presumably reduces maternal systemic or placental viral loads, thus decreasing the likelihood of fetal infection. Once the fetus is infected, however, hyperimmune globulin presumably reduces placental or fetal inflammation, or both, resulting in increased fetal blood flow with enhanced fetal nutrition and oxygenation. This mechanism may also account for the reversal of ultrasonographic abnormalities apparently associated with hyperimmune globulin therapy, since most signs and symptoms of congenital infection usually resolve during the first weeks of life, presumably owing to improved nutrition and oxygenation.

Serologic screening of asymptomatic women is common in Europe but less so in the United States. For our study, in 2000, we screened 1722 pregnant women, 401 (23 percent) of whom were seronegative and 31 ( 2 percent) of whom subsequently seroconverted. In the United States, the seroconversion rate is similar. ${ }^{4,29}$ Whether serologic screening during pregnancy is desirable remains undecided. Cost-benefit ratios need to be considered. Ultrasonography of the fetus at 20 weeks' gestation is, however, routine in many countries, including the United States. Our experience suggests this is a sen- sitive approach for predicting congenital disease due to CMV.

A limitation of our study was that it did not include random assignment. Our data should stimulate the initiation of randomized, controlled trials, possibly in the United States or other countries where maternal CMV screening is not routine, to provide additional data and unequivocally establish the degree of efficacy of hyperimmune globulin therapy and the optimal doses and dosing regimens.

Although CMV-specific hyperimmune globulin therapy was safe and appears to be associated with both effective therapy and the prevention of congenital infection, passive immunization is not an optimal solution. Our results indicate that active immunization is feasible. Several vaccines are being evaluated in clinical trials, and a vaccine that induces only maternal antibodies against CMV should be effective in this setting. ${ }^{30,31}$

We are indebted to the director of the Gynecological Sciences, Perinatology, and Child Health of La Sapienza University, Rome (Ermelando V. Cosmi), the director of the Department of Infectious Diseases, Institute G. Gaslini, University of Genoa (Dante Bassetti), and the director of the Obstetrical and Gynecological Department of the University of Perugia (Giancarlo Di Renzo), whose centers treated the majority of the patients who received HIG; to Nicola Carletti (Matera), Carlo Guidoni (Siena), Alessandro Mauri (Cagliari), Pasquale Pisano (Salerno), and Giuseppina Timpani (Reggio Calabria), who treated single patients; to Annamaria Bressan, Patrizia Birarel$\mathrm{li}$, and Sandro Valia for performing immunologic assays; to Paola Di Marco for viral isolation; and to Eleonora Sali, Paola Cervone, Daniela Di Ruzza, Andrea Costantini, Claudia D’Emilio, Giovanna Picone, Barbara Riosa, Romolo di Iorio, Luigi Reverberi, Ettore Palma, Viviana Cardilli, Salvatora Arachi, Renato Lucchini, Gianluca Sallustio, Fabio Natale, Mario Lituania, Giancarlo Barboni, Carla Lupi, Gianfranco Spennati, Francesco Carrera, Salvatore Catania, Sonia Tzantzoglou, Marcello Assumma, Rocco Agostino, Clemente Leo, and Modesto Mendicini for clinical collaboration.

A P PENDIX

In addition to the authors, the following investigators participated in the Congenital Cytomegalovirus Collaborating Group: R. Ceccarelli, P. Taverna (Institute G. Gaslini, University of Genoa, Genoa), G. Epicoco (Policlinico Monteluce, University of Perugia, Perugia), H. Pentimalli (San Giovanni/Addolorata Hospital, Rome), and M.M. Anceschi, Luca Maranghi, Manuela Mazzocco, G. Gentile, A. Capobianchi, A. Gaeta, and A. Nazzari (La Sapienza University, Rome).

REFERENCES

1. Stagno S. Cytomegalovirus. In: Remington JS, Klein JO, eds. Infectious diseases of the fetus and newborn infant. 5th ed. Philadelphia: W.B. Saunders, 2001:389-424.

2. Alford CA, Stagno S, Pass RF, Britt WJ Congenital and perinatal cytomegalovirus infections. Rev Infect Dis 1990;12:Suppl 7: S745-S753.

3. Stagno S, Whitley RJ. Herpesvirus infections of pregnancy. I. Cytomegalovirus and Epstein-Barr virus infections. N Engl J Med 1985;313:1270-4

4. Stagno S, Pass RF, Cloud G, etal. Primary cytomegalovirus infection in pregnancy: incidence, transmission to fetus, and clinical outcome. JAMA 1986;256:1904-8.

5. Nigro G, La Torre R, Anceschi MM, Mazzocco M, Cosmi EV. Hyperimmunoglobulin therapy for a twin fetus with cytomegalovirus infection and growth restriction. Am J Obstet Gynecol 1999;180:1222-6.

6. Volpe JJ. Neurology of the newborn. 4th ed. Philadelphia: W.B. Saunders, 2001.

7. Lubchenko LO. Assessment of gestational age and development of birth. Pediat Clin North Am 1970;17:125-45.
8. Snydman DR, Werner BG, Heinze-Lacey $B$, et al. Use of cytomegalovirus immune globulin to prevent cytomegalovirus disease in renal-transplant recipients. $\mathrm{N}$ Engl J Med 1987;317:1049-54.

9. Ballow M. Mechanisms of action of intravenous immune serum globulin therapy. Pediatr Infect Dis J 1994;13:806-11.

10. Clark AL, Gall SA. Clinical uses of intravenous immunoglobulin in pregnancy. Am J Obstet Gynecol 1997;176:241-53.

11. Keller MA, Stiehm ER. Passive immunity in prevention and treatment of infectious 
diseases. Clin Microbiol Rev 2000;13:60214.

12. Sawyer LA. Antibodies for the prevention and treatment of viral diseases. Antiviral Res 2000;47:57-77.

13. Nigro G, Mazzocco M, Anceschi MM La Torre R, Antonelli G, Cosmi EV. Prenata diagnosis of fetal cytomegalovirus infection following primary or recurrent maternal infection. Obstet Gynecol 1999;94:909-14.

14. Grangeot-Keros L, Mayaux MJ, Lebon P, et al. Value of cytomegalovirus (CMV) IgG avidity index for the diagnosis of primary CMV infection in pregnant women. J Infect Dis 1997;175:944-6.

15. Harrison CJ, Waner JL. Natural killer cell activity in infants and children excreting cytomegalovirus. J Infect Dis 1985;151:301-7. 16. Stites DP, Terr AI, Parslow TG. Medical immunology. 9th ed. Stamford, Conn.: Appleton \& Lange, 1997.

17. Hosmer DW, Lemeshow S. Applied logis tic regression. 2nd ed. New York: John Wiley, 2000.

18. Fowler KB, Stagno S, Pass RF. Materna immunity and prevention of congenital cytomegalovirus infection. JAMA 2003;289 1008-11.
19. Fowler KB, Stagno S, Pass RF, Britt WJ, Boll TJ, Alford CA. The outcome of congenital cytomegalovirus infection in relation to maternal antibody status. N Engl J Med 1992 326:663-7.

20. Adler SP, Chandrika T, Lawrence L, Baggett J. Cytomegalovirus infections in neonates acquired by blood transfusions. Pediatr Infect Dis 1983;2:114-8.

21. Yeager AS, Grumet FC, Hafleigh EB Arvin AM, Bradley JS, Prober CG. Prevention of transfusion-acquired cytomegalovirus infection in newborn infants. J Pediatr 1981;98:281-7.

22. Adler SP, Baggett J, Wilson M, Lawrence L, McVoy M. Molecular epidemiology of cytomegalovirus transmission in a nursery: lack of evidence for nosocomial transmission. J Pediatr 1986;108:117-23.

23. Bratcher DF, Bourne N, Bravo FJ, et al. Effect of passive antibody on congenital cytomegalovirus infection in guinea pigs. J Infect Dis 1995;172:944-50.

24. Chatterjee A, Harrison CJ, Britt WJ, Bewtra C. Modification of maternal and congenital cytomegalovirus infection by antiglycoprotein b antibody transfer in guine pigs. J Infect Dis 2001;183:1547-53.
25. Rook AH. Interactions of cytomegalovirus with the human immune system. Rev Infect Dis 1988;10:Suppl 3:S460-S467.

26. Dokun AO, Kim S, Smith HR, Kang HS, Chu DT, Yokoyama WM. Specific and nonspecific NK cell activation during virus infection. Nat Immunol 2001;2:951-6.

27. Sissons JG, Carmichael AJ, McKinney N, Sinclair JH, Wills MR. Human cytomegalovirus and immunopathology. Springer Semin Immunopathol 2002;24:169-85.

28. Fairweather D, Kaya Z, Shellam GR, Lawson CM, Rose NR. From infection to autoimmunity. J Autoimmun 2001;16:17586.

29. Adler SP. Cytomegalovirus and child daycare: evidence for an increased infection rate among caretakers. N Engl J Med 1989;321: 1290-6.

30. Pass RF, Duliege AM, Boppana S, et al. A subunit cytomegalovirus vaccine based on recombinant envelope glycoprotein $b$ and $a$ new adjuvant. J Infect Dis 1999;180:970-5. 31. Adler SP, Hempfling SH, Starr SE, Plotkin SA, Riddell S. Safety and immunogenicity of the Towne strain cytomegalovirus vaccine. Pediatr Infect Dis J 1998;17:200-6.

Copyright (c) 2005 Massachusetts Medical Society. 